\title{
Causal Nexus between Billing Efficiency and Economic Growth in India: An Analysis Using Vector Autoregression
}

\author{
Asit Ranjan Mohanty ${ }^{1}$, Devtosh Chaturvedi ${ }^{2}$ \& Suresh Kumar Patra ${ }^{3}$ \\ ${ }^{1}$ Professor in Finance, XIMB, Xavier University, Bhubaneswar, Odisha, India \\ ${ }^{2}$ Feedback Energy Distribution Company, Bhubaneswar, India \\ ${ }^{3}$ Centre of Excellence in Fiscal Policy and Taxation (CEFT), Xavier Institute of Management, Xavier University, \\ Bhubaneswar, Odisha, India
}

Correspondence: Asit Ranjan Mohanty, Professor in Finance, XIMB, Xavier University, Bhubaneswar, ODISHA, Pin: 751013, INDIA. Tel: 91-789-441-4730. E-mail: asit.mohanty@ximb.ac.in

Received: January 10, 2017

Accepted: February 15, 2017

Online Published: February 20, 2017

doi:10.5539/ijef.v9n3p184

URL: https://doi.org/10.5539/ijef.v9n3p184

\begin{abstract}
Energy being a major factor of production plays a pivotal role in inducing a sustained and high economic growth of an economy. This paper attempts to examine the Vector Autoregression (VAR) based Granger causality between billing efficiency and growth rate of per capita Gross Domestic Product (GDP) of India using annual time series data for the period 1970-71 to 2014-15. The conventional Augmented Dicky-Fuller and Phillips-Perron tests reveal that both the series are non-stationary and individually integrated of order one. Johansen-Juselius cointegration approach finds no evidence on the long-run equilibrium association between these variables. However, the VAR - based Granger causality approach reveals unidirectional causality running from billing efficiency to economic growth without any feedback effect. As regards policy implication, implementation of both the short term and long term measures in improving billing efficiency, through the enhancement of commercial and operational efficiency in electricity distribution sector will undoubtedly aid in achieving sustained and high economic growth in India.
\end{abstract}

Keywords: billing efficiency, economic growth, vector autoregression

\section{Introduction}

Availability of Energy is critical for the economic growth and social development of any economy. Electricity is the most important component of energy. As a crucial infrastructural input, it plays a pivotal role in socio-economic development of a country.

A plethora of empirical works exist on the association and the direction of causality between energy consumption and economic growth since 1970s (Kraft \& Kraft,1978; Akarca \& Long,1979; Erol \& Yu, 1987; Murry \& Dan, 1992; Eden \& Jin, 1992; Stern, 1993; Cheng, 1995; Cheng \& Lai, 1997; Glasure \& Lee, 1998; Ghosh, 2002; Lee, 2005; Narayan \& Smyth, 2005; Francis et al., 2007; Mehrara, 2007; Chen et al., 2007; Lee \& Chang, 2008; Sari et al., 2008; Bowden \& Payne, 2010). However, the relationship between billing efficiency and economic growth has received less scholarly attention. In this backdrop, an attempt has been made to examine the relationship between billing efficiency and economic growth in India for the period 1970-71 to 2014-15.

It is evident from the Table 1 that in a high economic growth phase, billing efficiency (Note 1) (BE) is high and in a low economic growth phase: billing efficiency is low. The trends in Fig.1 also explain the close association between economic growth and billing efficiency. Fig. 2 depicts the pro-cyclicality (Note 2) association between billing efficiency and economic growth. However, there exists the inverse relationship between billing efficiency and Transmission and distribution (T\&D) loss. High billing efficiency reduces T\&D loss which implied more billed energy and higher consumption of electricity. Thus, low billing efficiency is the main factor behind the overall inefficiency in the distribution sector.

India stands fourth in energy consumption in the world after the United States, China, and Russia. Being the base for multipurpose use, electricity acts as the mainstay of agricultural and industrial expansion of the Indian economy. The installed capacity (in MB) of power stations in India has soared to about $304760.75 \mathrm{MW}$ by the 
end of July 2016 (Note 3). Over the decades, a robust interstate and inter-regional transmission system have evolved enabling widespread reach of power over the vast area of the country. The per capita electricity consumption (total utilities) in India has risen from 28.85 units (KWh) in 1960 to about 582.29 units (KWh) in 2015 (Note 4). Despite its growing energy usage, India's per capita energy consumption remains at a very low level compared to the world average of 2,977 unit (KWh) (Note 5).

Around 840 million people in India do not have access to electricity, and they mostly live without clean cooking energy. Although India has possessed massive installed generation capacity (utilities) of over 298,060 MW for the last 69 years, transmission and distribution losses have remained at very high level. However, the installed capacity over 298,060 MW for the last 69 years fall short of install capacity required for the economy. Because of high Distribution losses, the perpetual deficit has further aggravated as compared to the energy requirements. During the year 2012-13, the country faced an energy deficit of 7.72\% and a peak shortage of 3.32\% (Note 6).

The billing efficiency in India is $78.54 \%$ in the year 2013-14 in India as against the global average of $91.37 \%$ (Note 7). This implies T\&D loss in India is $21.5 \%$. Globally, India is at $56^{\text {th }}$ position in terms T\&D loss. Out of T\&D loss, the transmission loss is at 3.5\% (Note 8) as against global benchmark of 5\%. Hence, low billing efficiency and high T\&D loss is mainly because of distribution loss. The distribution loss and low billing efficiency of the Electricity Distribution Companies (DISCOMs) are due to high technical and non-technical losses. To encourage private sector participation in the distribution sector, the private investors were offered a 16 percent return on equity with a full five-year tax holiday. However, to improve the efficiency of the distribution sector, negligible or no investments were made by the DISCOMS for improving the infrastructure, which was slowly getting outdated and obsolete.

Now, the concept of effective billing and collection efficiency draw both the national and international attention. Aggregate Commercial \& Technical loss which shows the overall inefficiency of a DISCOM is defined as AT \& C Loss (Note 9) $=(1-($ Billing Efficiency*Collection Efficiency $) * 100$. Billing Efficiency is: Billing Efficiency $(\%)=(1-\mathrm{T} \& \mathrm{D}$ Loss $) * 100$. Collection Efficiency $(\%)=($ Revenue realized $/$ Amount Billed to Consumers $) * 100$

The descriptive statistics of India and World relating to T\&D loss, billing efficiency, per capita consumption of electricity and per capita income are given in Table 2 for a comparative purpose.

The global average per capita consumption of electricity is 4.37 times of India's per capita consumption of electricity during this period. During this period, the average per capita income of the world is seven times of average per capita income of India. In this context, not only the higher generation of electricity but also the billing efficiency is important to induce the per capita income of India.

In general, an efficient billing system reduces AT\&C loss and improves the financials of the DISCOMS. Improvement in billing and collection activities has an instantaneous impact on the revenue generation of a service provider. Commercial and operational efficiencies by improving both billing and collection efficiency will generate more revenue, hence, the financial health of the DISCOMS. The commercial loss in India is around $6 \%$, therefore, billing inefficiency is the pivot for the distribution sector and the economy. Thus, efficient efficiency is an edifice upon which the sustained higher economic growth rests. Realizing the importance of billing efficiency, this paper attempts to analyze the relationship and the direction of causality between economic growth and billing efficiency in Indian context for the period 1970-71 to 2014-15. Since, to the best of our knowledge, no study has yet attempted the same, it will add value to the existing energy literature.

The rest of the paper is set out as follows. Section 2 explains the issues related to data and methodology about the empirical exercise was undertaken in the study. Empirical results examining the long-run association and the causal nexus between the billing efficiency and economic growth in India are discussed in Section 3. Finally, Section 4 concludes with policy implications.

Table 1. Trends in billing efficiency and economic growth

\begin{tabular}{lcc}
\hline Years & Billing efficiency (BE) & Per capita GDP Growth \\
\hline $1970 \mathrm{~s}$ & $80 \%$ & $9 \%$ \\
$1980 \mathrm{~s}$ & $78 \%$ & $12 \%$ \\
$1990 \mathrm{~s}$ & $76 \%$ & $13 \%$ \\
$2000 \mathrm{~s}$ & $70 \%$ & $11 \%$ \\
$2011-2015$ & $77 \%$ & $12 \%$ \\
\hline
\end{tabular}

Source: Authors' calculation. 
In 1970s, though Billing Efficiency is high, the per capita GDP growth is relatively less as compared to subsequent decades on account of lower productivity in the economy. This lower productivity was a constraint to translate higher billing efficiency into higher per capita economic growth.

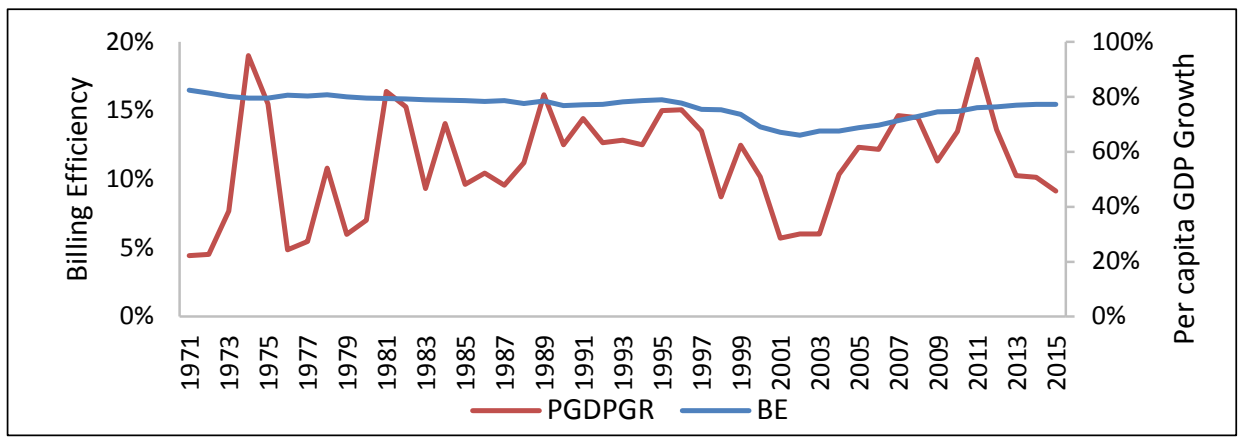

Figure 1. Trends in efficiency and per capita GDP growth rate

Source: Authors' calculation.

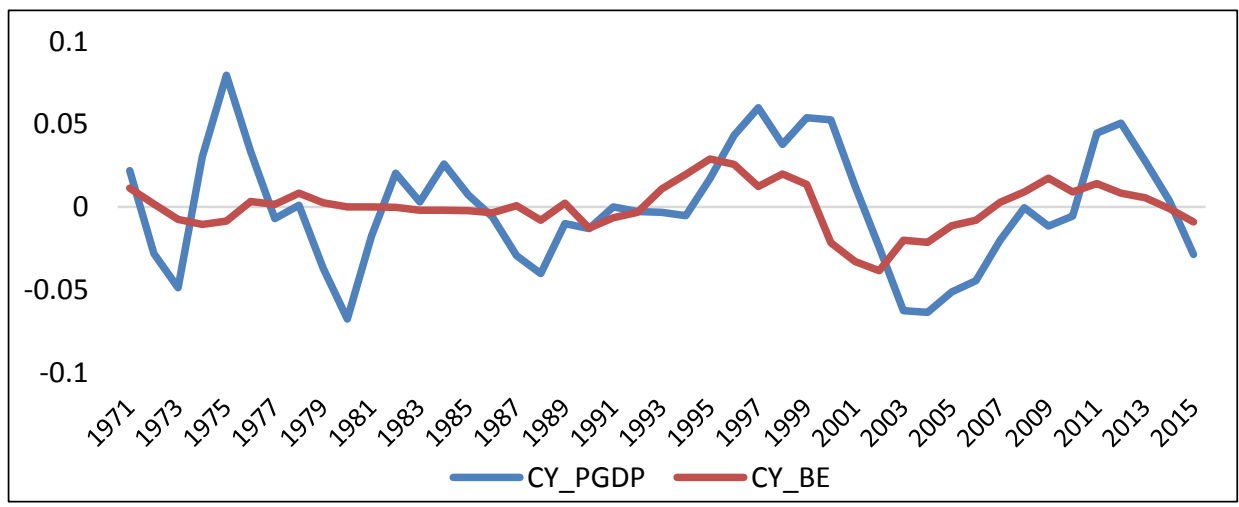

Figure 2. Cyclicality of per capita GDP and billing efficiency (HP filter)

Source: Authors' calculation.

Table 2. India's billing efficiency vs. global billing efficiency

\begin{tabular}{lccccc}
\hline Year & $2010-11$ & $2011-12$ & $2012-13$ & $2013-14$ & $2014-15$ \\
\hline India's Billing Efficiency & $78.76 \%$ & $76.03 \%$ & $76.35 \%$ & $76.96 \%$ & $78.54 \%$ \\
India's T\&D Loss & $21.24 \%$ & $23.97 \%$ & $23.65 \%$ & $23.04 \%$ & $21.46 \%$ \\
India's Per Capita Income (in USD) at Current Prices & 1387.88 & 1455.67 & 1444.27 & 1456.20 & 1576.82 \\
India's Per Capita Consumption(Unit) & 601.55 & 643.88 & 698.43 & 724.49 & 765.00 \\
Global Billing Efficiency & $91.27 \%$ & $91.37 \%$ & $91.30 \%$ & $91.39 \%$ & $91.37 \%$ \\
Global T\& D Loss & $8.73 \%$ & $8.64 \%$ & $8.70 \%$ & $8.61 \%$ & $8.63 \%$ \\
The World Per Capita Income(in USD) at Current Prices & 9481.63 & 10395.90 & 10498.46 & 10650.83 & 10757.29 \\
World's Per Capita Consumption (Unit) & 2798.27 & 2956.76 & 3021.38 & 3047.21 & 3104.38 \\
World Per capita consumption as the proportion of India's Per & \multirow{2}{*}{4.65} & 4.59 & 4.33 & 4.21 & 4.06 \\
Capita Consumption & & & & & \\
\hline
\end{tabular}

Source: CEA, GOI; World Bank, World Energy Council.

\section{Data and Methodology}

If two-time series variables are individually integrated of order one i.e. I(1) but their linear combination follows $\mathrm{I}(0)$ (i.e. they are cointegrated), then there would be a causal relationship at least in one direction (Engle \& Granger, 1987). Cointegration between two series solves the problem of 'spurious' correlation. Although, cointegration reflects the long-run association between two variables and confirms the existence of Granger causality between them but it does not reflect the direction of causality. The direction of causality between variables can be detected in Granger causality approach through VEC (Vector Error Correction) model of 
long-run cointegrating vectors. Adding to this, Granger's Representation Theorem also exhibits how to model a cointegrated I(1) series in a VAR (vector autoregression) format. VAR can be modeled either regarding the level of the data concerning their first difference i.e. $\mathrm{I}(0)$ variables, with the addition of an error correction term to capture the short-run dynamics.

If the series are I(1) but not cointegrated, causality test may give misleading results unless the data are transformed to induce stationarity (Ghosh, 2002).

\subsection{VAR (Vector Autoregression) Causality Test}

To test the causal nexus between billing efficiency and per capita GDP, we followed three stage procedure of Oxley and Greasley (1998). The first step is to identify the order of integration of these variables using the conventional Augmented Dickey-Fuller (ADF) and Phillips-Perron (PP) tests. Based on the outcome of unit root tests; in the second step, we investigated the bivariate cointegration using VAR approach of Johansen (1988, 1991) and Johansen and Juselius (1990). In the third step, we moved ahead to estimate VAR-based Granger causality test since the null hypothesis of 'no cointegration' is not rejected.

Three alternative approaches are available under the three stage procedure for examining the causality. If both the time series variables are independently integrated of order one and cointegrated then for examining Granger causality, we must use I(1) data because of the super consistency properties of estimation.

$$
\begin{gathered}
X_{t}=\alpha_{0}+\sum_{i=1}^{m} \alpha_{i} X_{t-i}+\sum_{j=1}^{n} \beta_{j} Y_{t-j}+v_{1 t} \\
Y_{t}=\gamma_{0}+\sum_{i=1}^{q} \theta_{i} Y_{t-i}+\sum_{j=1}^{r} \eta_{j} X_{t-j}+v_{2 t}
\end{gathered}
$$

Where $v_{1 \mathrm{t}}$ and $v_{2 \mathrm{t}}$ are zero-mean, serially uncorrelated, random disturbances.

Secondly, we may perform the Granger causality tests for cointegrated variables using $\mathrm{I}(0)$ data by introducing an error correction (ECM) term i.e.

$$
\begin{gathered}
\Delta X_{t}=\alpha_{0}+\sum_{i=1}^{m} \alpha_{i} \Delta X_{t-i}+\sum_{j=1}^{n} \beta_{j} \Delta Y_{t-j}+\delta E C M_{t-1}+v_{1 t} \\
\Delta Y_{t}=\gamma_{0}+\sum_{i=1}^{q} \theta_{i} \Delta Y_{t-i}+\sum_{j=1}^{r} \eta_{j} \Delta X_{t-j}+d E C M_{t-1}+v_{2 t}
\end{gathered}
$$

Thirdly, if two-time series variables follow I(1) but are not cointegrated, then for valid Granger causality test, it is required to transform these $\mathrm{I}(1)$ variables to $\mathrm{I}(0)$ by taking their first difference.

$$
\begin{aligned}
& \Delta X_{t}=\alpha_{0}+\sum_{i=1}^{m} \alpha_{i} \Delta X_{t-i}+\sum_{j=1}^{n} \beta_{j} \Delta Y_{t-j}+v_{1 t} \\
& \Delta Y_{t}=\gamma_{0}+\sum_{i=1}^{q} \theta_{i} \Delta Y_{t-i}+\sum_{j=1}^{r} \eta_{j} \Delta X_{t-j}+v_{2 t}
\end{aligned}
$$

In the present study, after carrying out the stationarity test of both ADF and PP, we confirm that both the variables i.e. BE (Billing Efficiency) and Lpgdp (log of per capita Gross Domestic Product) are stationary at first difference. Further, the Johansen-Juselius cointegration test also does not reveal any cointegration between these variables. Hence, following the third step, we estimated VAR causality by taking the first difference form of both $B E$ and Lpgdp. The main advantage of VAR approach is that the causality can be carried out in a setting where variables are allowed to be determined simultaneously. The VAR model for the present analysis can be represented as follows.

$$
\begin{gathered}
\Delta \operatorname{Lpgdp}_{t}=\alpha_{0}+\sum_{i=1}^{m} \alpha_{i} \Delta \operatorname{Lpgdp}_{t-i}+\sum_{j=1}^{n} \beta_{j} \Delta B E_{t-j}+v_{1 t} \\
\Delta B E_{t}=\gamma_{0}+\sum_{i=1}^{q} \theta_{i} \Delta B E_{t-i}+\sum_{j=1}^{r} \eta_{j} \Delta L p g d p_{t-j}+v_{2 t}
\end{gathered}
$$

Where the $v_{1 \mathrm{t}}$ and $v_{2 \mathrm{t}}$ are stochastic error terms, called impulses or innovations or shocks in the VAR language.

With the help of Akaike Information Criterion (AIC) and Hannan-Quinn information criterion (HQ), we determine the optimal lag length for $\mathrm{m}, \mathrm{n}, \mathrm{q}$, and $\mathrm{r}$.

Now, for equations (1) and (2), Y Granger causes $\mathrm{X}$ if,

$\mathrm{H}_{0}: \beta_{1}=\beta_{2}=\ldots \ldots=\beta_{n}=0$ is rejected 
against

$\mathrm{H}_{1}:=$ at least one $\beta_{j} \neq 0, j=1 \ldots . n$

and $\mathrm{X}$ Granger causes $\mathrm{Y}$ if, $\eta_{1}=\eta_{2}=\ldots \ldots=\eta_{n}=0$ is rejected against

$\mathrm{H}_{1}$ : at least one $\eta_{j} \neq 0, j=1 \ldots . . r$.

Similarly, for equation (3) and (4), $\Delta \mathrm{Y}$ Granger causes $\Delta \mathrm{X}$ if,

$\mathrm{H}_{0}: \beta_{1}=\beta_{2}=\ldots \ldots=\beta_{n}=0$ is rejected

against

$\mathrm{H}_{1}$ : =at least one $\beta_{j} \neq 0, j=1 \ldots . n$ or $\delta \neq 0$

and $\Delta \mathrm{X}$ Granger causes $\Delta \mathrm{Y}$ if, $\eta_{1}=\eta_{2}=\ldots \ldots=\eta_{n}=0$ is rejected against

$\mathrm{H}_{1}$ : at least one $\eta_{j} \neq 0, j=1 \ldots . r$ or $d \neq 0$.

For equation (5) and (6), $\Delta \mathrm{Y}$ Granger causes $\Delta \mathrm{X}$ if,

$\mathrm{H}_{0}: \beta_{1}=\beta_{2}=\ldots \ldots=\beta_{n}=0$ is rejected

against

$\mathrm{H}_{1}$ : =at least one $\beta_{j} \neq 0, j=1 \ldots . . n$,

and $\Delta \mathrm{X}$ Granger causes $\Delta \mathrm{Y}$ if, $\eta_{1}=\eta_{2}=\ldots \ldots=\eta_{n}=0$ is rejected against

$\mathrm{H}_{1}$ : at least one $\eta_{j} \neq 0, j=1 \ldots . . r$.

Finally, for equation (7) and (8), $\Delta B E$ Granger causes $\Delta L p g d p$ if,

$\mathrm{H}_{0}: \beta_{1}=\beta_{2}=\ldots \ldots=\beta_{n}=0$ is rejected against

$\mathrm{H}_{1}:=$ at least one $\beta_{j} \neq 0, j=1 \ldots . n$,

and $\triangle$ Lpgdp Granger causes $\triangle B E$ if, $\eta_{1}=\eta_{2}=\ldots \ldots . .=\eta_{n}=0$ is rejected against

$\mathrm{H}_{1}$ : at least one $\eta_{j} \neq 0, j=1 \ldots . . r$.

For the empirical analysis, we calculated per capita Gross Domestic Product (PGDP) and Billing Efficiency (BE) for the period 1970-71 to 2014-15. Per capita GDP is calculated by dividing Gross Domestic Product with respect population. Data on population and GDP at current prices (at 2004-05 $=100$ ) are obtained from the Handbook of Statistics on Indian Economy, 2014-15, published by Reserve Bank of India (RBI). Billing efficiency is calculated as billed energy as a proportion of input energy. Input Energy is defined as the total amount of energy purchased by utilities from the generation company. Therefore, billing efficiency captured the transmission and distribution losses ( $\mathrm{T} \& \mathrm{D}$ loss).

Data on energy billed to consumers in the unit and total input energy in the unit are collected from 'Public Electricity Supply, All India Statistics' published by Central Electricity Authority of India.

\section{Result Analysis}

In the present study, we checked the unit root property of both the variables such as billing efficiency (BE) and per capita GDP ( $L p g d p)$ in the first stage. The conventional Augmented-Dicky Fuller (ADF) and Phillips-Perron (PP) unit root tests were performed for this. The null hypothesis of a unit root at level is accepted for both the variable cases while it is rejected in the first difference. Hence, from both the ADF and PP unit root tests, we conclude that both the variables billing efficiency and per capita GDP follow I(1) i.e. they are integrated of order one. Unit root result is presented in Table 3.

Table 3. Results of unit root test

\begin{tabular}{cccccc}
\hline \multirow{2}{*}{ Variables } & \multicolumn{3}{c}{ ADF Test } & \multicolumn{3}{c}{ PP Test } \\
\cline { 2 - 6 } & Level & First Difference & Level & First Difference & Inference \\
\hline \multirow{2}{*}{$\boldsymbol{B} \boldsymbol{E}$} & -2.52 & $-4.06^{*}$ & -1.40 & $-3.94^{*}$ & $\mathrm{I}(1)$ \\
& $(0.32)$ & $(0.00)$ & $(0.85)$ & $(0.00)$ & \\
\multirow{2}{*}{$\boldsymbol{L p g d \boldsymbol { d }}$} & -2.62 & $-4.53^{*}$ & -2.51 & $-4.69^{*}$ & $\mathrm{I}(1)$ \\
& $(0.27)$ & $(0.00)$ & $(0.32)$ & $(0.00)$ & \\
\hline
\end{tabular}

Note. '*' denotes significance at $1 \%$ level.

In the second stage, cointegration is checked through Johansen-Juselius (JJ) maximum likelihood procedure. 
This method deals with a unified structure for assessing and testing of the long-run association between variables in the context of a Vector Autoregression (VAR) error correction model. The results of the JJ maximum likelihood test are depicted in Table 4.

Table 4. Johansen-Juselius likelihood cointegration tests ${ }^{\#}$

\begin{tabular}{lccc}
\hline Null & Alternative & Statistic & $90 \%$ Critical Value \\
\hline$\lambda_{\text {trace }}$ test & & & \\
$\mathrm{r}=0$ & $\mathrm{r}>0$ & 6.15 & 13.42 \\
$\mathrm{r} \leq 1$ & $\mathrm{r}>1$ & 0.002 & 2.70 \\
$\lambda_{\max }$ test & & & \\
$\mathrm{r}=0$ & $\mathrm{r}=1$ & 6.14 & 12.29 \\
$\mathrm{r}=1$ & $\mathrm{r}=2$ & 0.002 & 2.71 \\
\hline
\end{tabular}

\# $r$ implies the number of cointegrating relations.

The JJ test result concludes that there is no cointegrating relationship between $B E$ and Lpgdp. The trace test does not reject the null hypothesis of 'no cointegration' among the variables i.e. $r=0$ as the value of trace statistic (6.15) is less than the 90 percent critical value (13.42). Hence, the null hypothesis of no cointegration cannot be rejected at 10 percent level of significance. Similarly, the maximal eigenvalue test does not reject the null hypothesis of 'no cointegration' at 10 percent level of significance. Hence, it is concluded from the JJ test that both the variables $B E$ and $L p g d p$ are not cointegrated.

After the confirmation of 'no cointegration' between $B E$ and Lpgdp, in the third stage, we moved to estimate the relationship between these two variables under the bivariate unstructured VAR framework. Using the first difference operator for $B E$ and Lpgdp, we applied unrestricted VAR. Lag 2 is chosen as the optimal lag order for VAR on the basis of Akaike Information Criterion (AIC) and Hannan-Quinn information criterion (HQ).

\subsection{Results of Vector Autoregression Model}

Table 5 below depicts the results of VAR model. In the DLpgdp regression model, DLpgdp at lag 1, DLpgdp at lag 2 and $D B E$ at its lag 2 are statistically significant. But, the $\mathrm{F}$ value is so high that we cannot reject the hypothesis that collectively all the lagged terms are statistically significant. Turning to the $D B E$ regression, we observe that all the lagged $D B E$ terms are individually statistically significant whereas no lagged $D L p g d p$ term is significant in the model. It states that billing efficiency in lag 2 has significant and positive effect on economic growth as the coefficient of $D B E(-2)$ is positive and significant in the DLpgdp regression.

Table 5. Estimates of vector autoregression model

\begin{tabular}{lcc}
\hline Vector Autoregression (VAR) Estimates & DLpgdp & DBE \\
\hline Lpgdp $(-1)$ & $0.38^{* *}$ & -0.03 \\
& {$[2.51]$} & {$[-0.54]$} \\
Dlpgdp $(-2)$ & $-0.33^{* *}$ & -0.003 \\
& {$[-2.32]$} & {$[-0.05]$} \\
DBE $(-1)$ & 0.12 & $0.31^{* * * *}$ \\
& {$[0.29]$} & {$[1.95]$} \\
DBE $(-2)$ & $0.79^{* * *}$ & $0.30^{* * *}$ \\
C & {$[1.89]$} & {$[1.90]$} \\
& $0.11^{*}$ & 0.004 \\
Fvalue & {$[5.48]$} & {$[0.51]$} \\
\hline
\end{tabular}

Note. '*', '**' and '***' denote level of significance at $1 \%, 5 \%$ and $10 \% ; \mathrm{t}$ values are given in parentheses.

Now, the study proceeds towards VAR Granger Causality or Block Exogeneity Wald test to know the causality between billing efficiency and economic growth.

Table 6. VAR granger causality/block exogeneity wald tests

\begin{tabular}{|c|c|c|c|}
\hline Null Hypothesis & $\chi^{2}$ & P-Value & Causal Relation \\
\hline$D B E$ does not Granger cause $\quad$ DLpgdp & $4.96^{* * *}$ & 0.08 & \multirow{2}{*}{$D B E \rightarrow D L p g d p$} \\
\hline DLpgdp does not Granger cause $D B E$ & 0.35 & 0.84 & \\
\hline
\end{tabular}

Note. * Denotes the rejection of null hypothesis at 1 per cent level. 
Table 6 clearly states that causality runs from DBE to DLpgdp but not from DLpgdp to DBE. Thus, billing efficiency influence economic growth but not vice-versa during the period 1971-2015 in India.

\subsection{Impulse Response Function (IRF)}

The impulse response function is a shock to the VAR system. The impulse responses identify the responsiveness of the dependent variable in the VAR when a shock is given to error terms such as $\varepsilon_{1 \mathrm{t}}$ and $\varepsilon_{2 \mathrm{t}}$ at the equation given above. A unit shock is applied to each variable and the results of the effects of a unit shock on the entire VAR system is presented in the Fig.3. A unit shock in $D B E$, in turn, affects $D L p g d p$ positively which supports the results obtained through VAR Granger Causality Test. With a unit shock of DBE, DLpgdp picks up sharply up to three periods and then it converges at the period 6. After that, it becomes negligible. Concisely, it can be observed from this figure that, the response of billing efficiency to the impulse of per capita GDP rate is negligible in the first period (close to zero in absolute value). In the second period, for change in one standard deviation of Billing efficiency, the growth rate of per capita GDP rises to $0.09 \%$. After that, it gradually converges and becomes negligible by the 6th period.

Similarly, as a result of a shock (standard deviation) in per capita GDP, the initial level of billing efficiency rises slightly $0.03 \%$. But, it becomes negative after that in the second and third periods. Afterward, it converges. Thus, from this impulse response analysis of the standard VAR, we found evidence of the strong influence of billing efficiency on per capita GDP growth but not vice versa.

Response to Cholesky One S.D. Innovations \pm 2 S.E.

Response of DLPGDP to DBE

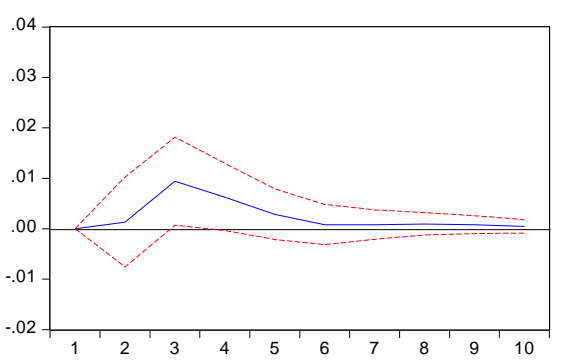

Response of DBE to DBE

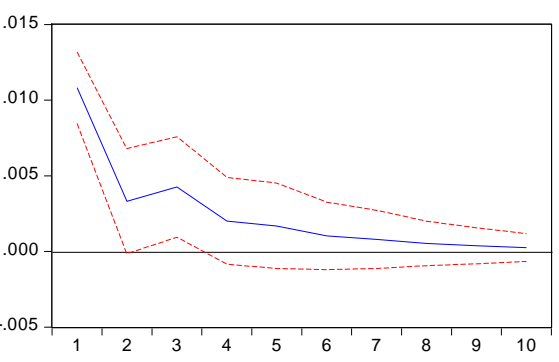

Response of DLPGDP to DLPGDP

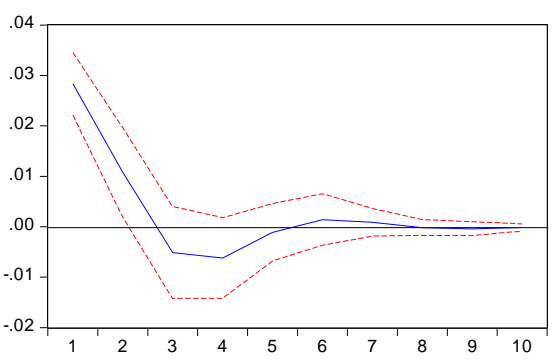

Response of DBE to DLPGDP

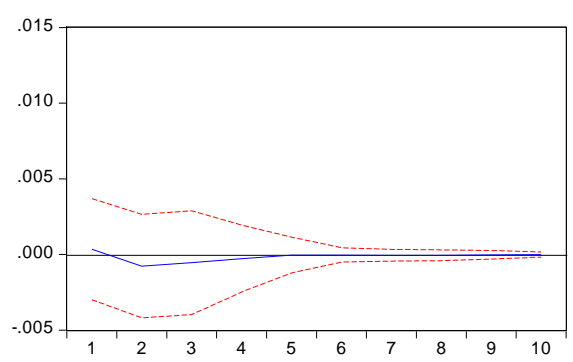

Figure 3. Impulse response function

\subsection{Variance Decomposition (VDC)}

The results of variance decomposition are reported in Table 7. To convey a sense of the dynamic of the VAR system, a ten-period horizon is employed.

Table 7. Variance decomposition

\begin{tabular}{clccccc}
\hline \multirow{2}{*}{ Period } & \multicolumn{2}{c}{ Variance Decomposition of DLpgdp: } & \multicolumn{3}{c}{ Variance Decomposition of DBE: } \\
\cline { 2 - 6 } & S.E. & DLpgdp & DBE & S.E. & DLpgdp & DBE \\
\hline 1 & 0.028 & 99.89 & 0.10 & 0.011 & 0.00 & 100.00 \\
2 & 0.030 & 99.62 & 0.38 & 0.011 & 0.60 & 99.39 \\
3 & 0.032 & 91.41 & 8.58 & 0.012 & 0.84 & 99.15 \\
4 & 0.033 & 88.72 & 11.28 & 0.012 & 0.89 & 99.10 \\
5 & 0.033 & 88.11 & 11.89 & 0.012 & 0.89 & 99.11 \\
6 & 0.033 & 88.07 & 11.93 & 0.012 & 0.88 & 99.11 \\
\hline
\end{tabular}




\begin{tabular}{ccccccc}
\hline 7 & 0.034 & 88.03 & 11.97 & 0.012 & 0.89 & 99.11 \\
8 & 0.034 & 87.959 & 12.05 & 0.012 & 0.89 & 99.11 \\
9 & 0.034 & 87.92 & 12.08 & 0.013 & 0.89 & 99.11 \\
10 & 0.034 & 87.90 & 12.09 & 0.013 & 0.89 & 99.11 \\
\hline \multicolumn{7}{c}{ Cholesky Ordering: DBE DLpgdp } \\
\hline
\end{tabular}

Similarly, the results from Table 5 show the decomposition of forecast error variance and the standard error shows the significance level of the variables. The results indicate that about 99 percent variation in DLpgdp is explained by its own shock in the first and second period. Whereas only 0.10 percent and 0.38 per cent variations are explained by $D B E$ at first and second steps respectively. In the third period, 8.58 per cent variation on $D L p g d p$ is explained by DBE. Thereafter, between the period 4 to 12 , about 11 to 12 per cent variations on $D L p g d p$ are explained by $D B E$. Contrary to this, the result indicates that 100 percent variation in $D B E$ is explained by its own shock in the first period. About 99 per cent variation in $D B E$ is explained by its own shock for the other 9 periods. Thus, the Granger-causal chain implied by the analysis of variance decomposition tends to explain that $D B E$ time series is the leading variable in explaining $D L p g d p$ but the converse is not true.

\section{Conclusion}

Energy being a major factor of production plays a pivotal role in achieving sustained and high economic growth in an economy. Electricity is a key component of energy upon which both the socio-economic and infrastructural development are based upon. The consumption of electricity largely depends on the billing efficiency. Improved billing and collection system has an immediate impact on the revenue generation of the distribution utility entity. Billing efficiency, essentially, improves the operational efficiency of the electricity distribution sector that resulted into better financials. Thus, efficient billing is an edifice upon which the sustained economic growth depends on. Taking cognizance of the close association between billing efficiency and economic growth, we attempted to examine the cointegration and dynamic causal nexus between them for the period 1970-71 to 2014-15 in the Indian context. To achieve this objective, we followed three stage procedures of Oxley and Greasley (1998).

In the first stage, the unit root test results suggested that both the time series variables namely billing efficiency and economic growth are stationary at first difference. Based on the unit root results, we performed Johansen-Juselius cointegration technique in the second step. However, it concluded that no cointegration between billing efficiency and economic growth exists. Hence, we applied Vector Autoregression framework to examine the causal direction between these variables in the third stage.

The estimated VAR - based Granger Causality or Block Exogeneity Wald test confirmed unidirectional causality that spreads from billing efficiency to economic growth. Further, both the impulse response function and variance decomposition also evidenced that billing efficiency has a relatively stronger effect on economic growth.

Since billing efficiency causes economic growth; hence, the government and electricity providers should take necessary actions to increase billing efficiency. Improvement in billing efficiency will reduce the overall power leakages and will reduce AT\&C loss.

Billing efficiency can be enhanced by strengthening billing coverage and billing quality. The billing coverage refers to billed consumer relative to paid consumers who are having meters. Billing quality refers to accuracy of the billing amount in accordance with the applicable tariff. Further, to reduce billing inefficiency, both short-term, and long-term measures should be taken immediately. Short-term measures include network reconfiguration and reconductoring, preventive measures at insulators, adding automated voltage boosters, load balancing, and load management, the increase in HT: LT ratio, adoption of the high voltage distribution system (HVDS), the creation of more primary substation. The long-term measures include GIS-based consumer indexing and electrical network mapping, Automated Meter Reading (AMR), Energy Audit and Accounting, Meter Data Logging System, Aerial Bunched Cables (ABC), Static energy meters, Time-of-day (TOD) Metering, etc. Therefore, investment in CAPEX and O\&M activities are the key to improving the billing efficiency. Higher billing efficiency is to be followed by higher collection efficiency as it ultimately provides revenue to utilities. If billing efficiency is high and collection efficiency is low, then it leads to loss in revenue to utilities. This loss in revenue is entirely borne by the utilities as it is neither compensated by grant or subsidies.

Implementation of both short term and long term measures will improve billing efficiency, thereby increasing the overall efficiency of the electricity distribution sector. Improvement in billing efficiency will help in reducing financial losses, which in turn, will help in reducing the tariff rate. Electricity theft and pilferage are also major 
concerns in the distribution sector. Adequate measures should be taken at the earliest to minimize theft and unauthorized connection. Most importantly, billing efficiency facilitates the enhancement of commercial and operational efficiency, the better financial position of the distribution utilities and aid in achieving sustained and high economic growth in India.

Since India is a power deficit country with leaking buckets in the distribution sector, the holes are deliberately made to collect economic rents by various stakeholders that control the system. Therefore, the efficiency of the electricity in distribution sector is more important than generation sector in India. Improvement in billing efficiency and reducing AT\& C loss will help in meeting the demand for electricity in the country for higher economic growth.

\section{References}

Akarca, A. T., \& Long, T. V. (1979). Energy and employment: A time-series analysis of the causal relationship. Resources and Energy, 2(2), 151-162. https://doi.org/10.1016/0165-0572(79)90027-6

Bowden, N., \& Payne, J. E. (2010). Sectoral analysis of the causal relationship between renewable and non-renewable energy consumption and real output in the US. Energy Sources, Part B: Economics, Planning, and Policy, 5(4), 400-408. https://doi.org/10.1080/15567240802534250

Chen, S. T., Kuo, H. I., \& Chen, C. C. (2007). The relationship between GDP and electricity consumption in 10 Asian countries. Energy Policy, 35(4), 2611-2621. https://doi.org/10.1016/j.enpol.2006.10.001

Cheng, B. S. (1995). An investigation of cointegration and causality between energy consumption and economic growth. Journal of Energy and Development, 21(1).

Cheng, B. S., \& Lai, T. W. (1997). An investigation of co-integration and causality between energy consumption and economic activity in Taiwan. Energy Economics, 19(4), 435-444. https://doi.org/10.1016/S0140-9883(97)01023-2

Eden, S. H., \& Jin, J. C. (1992). Cointegration tests of energy consumption, income, and employment. Resources and Energy, 14(3), 259-266. https://doi.org/10.1016/0165-0572(92)90010-E

Engle, R. F., \& Granger, C. W. (1987). Co-integration and error correction: Representation, estimation, and testing. Econometrica: Journal of the Econometric Society, 251-276. https://doi.org/10.2307/1913236

Erol, U., \& Yu, E. S. (1987). On the causal relationship between energy and income for industrialized countries. Journal of Energy and Development, 13(1), 113-122.

Francis, B. M., Moseley, L., \& Iyare, S. O. (2007). Energy consumption and projected growth in selected Caribbean countries. Energy Economics, 29(6), 1224-1232. https://doi.org/10.1016/j.eneco.2007.01.009

Ghosh, S. (2002). Electricity consumption and economic growth in India. Energy Policy, 30(2), 125-129. https://doi.org/10.1016/S0301-4215(01)00078-7

Glasure, Y. U., \& Lee, A. R. (1998). Cointegration, error-correction, and the relationship between GDP and energy: The case of South Korea and Singapore. Resource and Energy Economics, 20(1), 17-25. https://doi.org/10.1016/S0928-7655(96)00016-4

Johansen, S. (1988). Statistical analysis of cointegration vectors. Journal of Economic Dynamics and Control, 12(2), 231-254. https://doi.org/10.1016/0165-1889(88)90041-3

Johansen, S. (1991). Estimation and hypothesis testing of cointegration vectors in Gaussian vector autoregressive models. Econometrica: Journal of the Econometric Society, 1551-1580. https://doi.org/10.2307/2938278

Johansen, S., \& Juselius, K. (1990). Maximum likelihood estimation and inference on cointegration-with applications to the demand for money.Oxford Bulletin of Economics and statistics, 52(2), 169-210. https://doi.org/10.1111/j.1468-0084.1990.mp52002003.x

Kraft, J., \& Kraft, A. (1978). The relationship between energy and GNP. J. Energy Dev.;(United States), 3(2).

Lee, C. C. (2005). Energy consumption and GDP in developing countries: A cointegrated panel analysis. Energy Economics, 27(3), 415-427. https://doi.org/10.1016/j.eneco.2005.03.003

Lee, C. C., \& Chang, C. P. (2008). Energy consumption and economic growth in Asian economies: A more comprehensive analysis using panel data. Resource and energy Economics, 30(1), 50-65. https://doi.org/10.1016/j.reseneeco.2007.03.003

Mehrara, M. (2007). Energy consumption and economic growth: The case of oil exporting countries. Energy Policy, 35(5), 2939-2945. https://doi.org/10.1016/j.enpol.2006.10.018 
Murry, D. A., \& Dan, G. D. (1992). The energy consumption and employment relationship: A clarification. Journal of Energy and Development;(United States), 16(1).

Narayan, P. K., \& Smyth, R. (2005). Electricity consumption, employment and real income in Australia evidence from multivariate Granger causality tests. Energy Policy, 33(9), 1109-1116. https://doi.org/10.1016/j.enpol.2003.11.010

Oxley, L., \& Greasley, D. (1998). Vector autoregression, cointegration and causality: Testing for causes of the $\begin{array}{lllll}\text { British industrial revolution. Applied } & \text { Economics, 30(10), 1387-1397. }\end{array}$ https://doi.org/10.1080/000368498325002

Sari, R., Ewing, B. T., \& Soytas, U. (2008). The relationship between disaggregate energy consumption and industrial production in the United States: an ARDL approach. Energy Economics, 30(5), 2302-2313. https://doi.org/10.1016/j.eneco.2007.10.002

Stern, D. I. (2000). A multivariate cointegration analysis of the role of energy in the US macroeconomy. Energy Economics, 22(2), 267-283. https://doi.org/10.1016/S0140-9883(99)00028-6

\section{Notes}

Note 1. Billing Efficiency $(\%)=($ Energy Billed to Consumers in unit / Total Input Energy in unit $) * 100$.

Note 2. Cyclical components are obtained by detrending the respective series using Hodrick-Prescott (HP) Filter.

Note 3. Central Electrical Authority, GOI.

Note 4. Ibid.

Note 5. Ibid.

Note 6. Ministry of Power, GOI.

Note 7. International Energy Agency, 2015.

Note 8. Ibid.

Note 9. Electricity Act, 2003 of GOI has introduced AT\&C loss to measure the overall inefficiency of the distribution utility.

\section{Copyrights}

Copyright for this article is retained by the author(s), with first publication rights granted to the journal.

This is an open-access article distributed under the terms and conditions of the Creative Commons Attribution license (http://creativecommons.org/licenses/by/4.0/). 